them under the disadvantageous conditions found in these areas was scarcely covered by the value of the by-products. But by increasing the value of these products the scale may be turned, and such a system rendered profitable, and it would certainly be an advantage to these areas to have such a supply of oil and cattle and other foods as these by-products would yield. Again, there are other areas where cotton is struggling against the rivalry of other competing crops, and where the scale might just be turned in its favour by the increased value of its by-products. Reference was made to the position of India, where the seed-crushing industry has never been properly developed, and it was agreed that such a process as the seed-lint removal might make all the difference.

A seed-lint defibrating machine was shown working at the lecture, and samples of all the by-products were exhibited, including bread, scones, and cakes made with a proportion of cotton-seed flour. There was a very useful discussion after the lecture by a number of experts representing different sections of the trades affected.

\section{A BRITISH GEODETIC AND GEODYNAMIC INSTITUTE.}

A COMMITTEE, consisting of Dr. Shipley (the A Vice-Chancellor), Dr. H. K. Anderson, Col. Sir C. F. Close, Sir Horaee Darwin, Sir F. W. Dyson, Dr. E. H. Griffiths, Sir T. H. Holdich, Sir Joseph Larmor, Col. H. G. Lyons, Prof. Newall, Sir Charles Parsons, Sir Napier Shaw, Sir J. J. Thomson, and Prof. H. H. Turner, has been formed for the purpose of making an appeal for the creation and endowment of a geophysical institute at Cambridge. The question of the establishment of an institute of this character has been under consideration by the British Association for the last three years. A large and representative committee reported unanimously in favour of the project, which was then considered by the Conjoint Board of Scientific Societies. This Board also reported that there was a real need for such an institute. The chief reasons which have been put forward on behalf of the scheme are:-(I) Geodetic work must form the basis and control of all the State surveys of the Empire, on which about a million sterling was spent annually before the war. (2) A geophysical institute could render great assistance in connection with the particular group of geodetic problems now of most practical interest in the United Kingdom, namely. those associated with levelling, mean sea-level, and vertical movements of the crust of the earth. (3) Such an institute is greatly needed to assist in the study of the tides and in attacking the great problems which must be solved if tidal prediction is to advance beyond its present elementary and fragmentary state. (4) There is at present no provision for the collection and critical discussion of the geodetic work which is being done within the Empire, or for its comparison with the work of other countries. There is no institution available for research work or higher training in geodesy. There is no British institution which can be referred to for the latest technical data and methods, and until the outbreak of war it was the custom of many British surveys (notably the Survey of India), when confronted with geodetic problems, to refer to the Geodetic Institute at Potsdam. This was not even then a very satisfactory arrangement, and now a radical change is inevitable.

Discussion as to where the institute could most suitably be established has led to the selection of Cambridge, for it is essential that an institute of geodesy and geodynamics should be closely associated with a great school of mathematics and physics, and

NO. 2582 , VOL. IO3] it is only in connection with a great Imperial university that that width and freshness of outlook are to be sought which are essential to a progressive and practical science. The committee has evidence that an institute at Cambridge would be cordially welcomed by the national Survey Departments, both terrestrial and oceanographic.

It is estimated that an endowment of $50,000 l$. will be necessary if the proposed institute is satisfactorily to perform the double task of research and education, but it is hoped that if half that sum were contributed by private benefactions the remainder would be forthcoming from national funds. An essential part of the scheme would be the foundation of a university professorship of geodynamics to be held by the director of the institute. To place this professorship in line with other chairs recently endowed by private benefactions, and usually associated with the names of the donors or founded as memorials of national sacrifice in the great war, a sum of $20,000 l$. (which is included in the 50,oool. mentioned above) would be required. It is certain that all who have to do with our shipping interests or with aerial navigation would ultimately profit from the establishment of such an institute.

\section{RESPONSIBILITIES OF BOTANICAL} SCIENCE.

SOME Responsibilities of Botanical Science" is the subject of Prof. B. E. Livingston's address to the Botany Section of the American Association for the Advancement of Science meeting at Baltimore last December (Science, February 28, I9I9). The work of botanical science is at present carried on by a sort of guerrilla warfare, each man for himself; for a planned and productive campaign co-operation is necessary. The objects to be attained are twofold. The first is the conservation of knowledge already attained. The existing means for presenting botanical abstracts and résumés are merely makeshifts; there is need for a national or international institute for the furnishing of bibliographical information on request. Such an institute would be a great undertaking, with a permanent staff of departmental heads and a corps of bibliographical assistants; but it would seek the co-operation of all men of science. It would avoid enormous waste of time and energy on the part of scientific workers and research institutions, and give congenial employment to many who wish to serve in scientific work, but may not find their best places as teachers or research workers.

The second object is botanical research, which is considered under three heads: the planning of research, the procuring of data, and the interpretation and presentation of results. Prof. Livingston emphasises the absence of any recognition of the investigator as such, and the striking characteristic that most of the published work apoears to be done by apprentices. The planning of scientific investigation deserves much more attention than it generally receives, and our selection of problems and planning of projected investigations would be greatly improved if co-operation between competent thinkers were more in vogue. The securing of the requisite observational or experimental data is the easiest part of investigation, but comparatively few writers trouble to interpret their results in a logically complete manner. A discussion is written from the point of view of one out of several or many logically possible hypotheses, and one of the greatest wastes in biological research lies in the publication of so many uninterpreted observations. Finally, there are the responsibilities towards applied botanical science, not only the practical applications in the arts, but also the philosophical applications to other branches of science. 